\title{
DAUR HIDUP PRODUK DAN ALIH TEKNOLOGI : DEKONSTRUKSI INDUSTRI NASIONAL
}

\author{
Anton Agus Setyawan \\ Fakultas Ekonomi Universitas Muhammadiyah Surakarta
}

\begin{abstract}
Technology becomes a major variable in the global industry. This phenomenon effects on the world's economic structure due to the technological disparity between developed countries and developing ones. As a developing country, Indonesia faces the same problem with any other ones. The disparity could be analyze by correlating the global product life cycle and the technology transfer process. The conclussion is, technology transfer from developed countries to developing ones happens when the product mature and obsolence. To overcome this problem, Indonesia have to focus on a few points, which are: maintaining local knowledge, industrial deconstruction, intellectual capital enforcement and building the rich land and big people paradigm.
\end{abstract}

\section{PENDAHULUAN}

Teknologi, sebuah kata yang populer saat dunia memasuki abad 21 ini. Kemajuan perekonomian suatu negara tidak dapat dipisahkan dari perkembangan teknologi negara tersebut. Bahkan bisa dikatakan "People who don't buy (or own) technology aren't going to be successful in the long run" (Soemardi, 1996). Pada gilirannya penguasaan teknologi akan meningkatkan bargaining position suatu negara, baik dalam konteks ekonomi maupun politik. Keunggulan hegemoni negara-negara maju, seperti AS, Jepang dan negara-negara Eropa, selain karena kekuatan militer, juga disebabkan oleh penguasaan mereka akan high-tech.

Keinginan mewujudkan dunia yang terintegrasi atau populer dengan istilah globalisasi, kian memicu kemajuan teknologi. Gejala ini semakin menguat seiring dengan keinginan negara-negara maju 
untuk mengekspor ideologi mereka ke negara-negara berkembang (Goldsmith, 1995). Kebijakan ini didukung penuh oleh perusahaanperusahaan multinasional, yang mempunyai motif ekonomi tersembunyi. Pada prakteknya, perusahaan-perusahaan multinasional tersebut adalah field agents globalisasi. Dan di tangan merekalah inovasi teknologi yang berkelanjutan terus dilakukan. Bahkan di dalam perusahaan-perusahaan tersebut Divisi R\&D menjadi ujung tombak perusahaan.

Tetapi perkembangan teknologi membawa preseden negatif terhadap pemerataan kesejahteraan dunia. Kondisi ekonomi dunia menuju Tata Ekonomi Dunia Baru, yang berorientasi pada pemerataan kesejahteraan Negara Maju-Berkembang malah kian jauh dari kenyataan. Hal ini didasarkan pada kenyataan bahwa negara-negara maju yang menjadi pelopor kemajuan teknologi, enggan untuk membagi pengetahuan mereka kepada negara-negara berkembang. Pada akhirnya asimetri perdagangan internasional, seperti yang diungkapkan Raul Prebisch, menjadi kenyataan yang tak terelakkan karena disparitas kemajuan teknologi negara maju-berkembang (A. Isaak, 1995).

Kondisi ini terjadi pula di Indonesia. Sebagai sebuah negara yang mengalami transisi menuju industrialisasi, Indonesia mengalami masalah dalam inovasi teknologi. Industri Indonesia masih berorientasi pada imported technologies bukannya pada research and development technologies. Pada akhirnya industrialisasi di Indonesia masih bersifat padat karya dengan penguasaan teknologi yang masih rendah.

\section{PRODUK GLOBAL $=$ HIGH TECH}

Perkembangan teknologi yang demikian pesat mengubah wajah dunia industri secara radikal. Dalam kurun waktu lebih kurang 20 tahun, industri global menuju pada tatanan baru semenjak digunakannya teknologi komputer di dalam sektor industri. Teknologi komputer hanya sebagian dari wajah industri global, meskipun teknologi tersebut merupakan pioneer dari perubahan ini. Adapun inti dari perkembangan teknologi adalah cara berpikir inovatif. Wujud nyata dari perkembangan teknologi adalah produk-produk global yang saat ini memiliki posisi penting dalam struktur ekonomi dunia. 
Produk global adalah produk yang memiliki availability by area yang meliputi 3-5 benua pada kurang lebih 101 negara (Budhi Setiawan, 1996). Hampir semua perusahaan multinasional di dunia memproduksi kategori produk ini. Perkembangan produk global banyak ditentukan oleh kualitas teknologinya. Satu contoh, perkembangan produk-produk software dari Microsoft yang selalu unggul dalam teknologi, pada akhirnya menjadi market leader di dalam pasarnya. Dan pada umumnya produk-produk tersebut dilindungi dengan intellectual property rights, sehingga memiliki paten tinggi. Pengertian produk global ini tidak hanya meliputi sektor manufaktur, tetapi juga mencakup sektor jasa. Bahkan pada perkembangannya sektor jasa mengalami peningkatan yang signifikan.

Melihat perkembangan produk global ini, sudah dapat di tebak, bahwa hanya negara-negara majulah yang memiliki kemampuan dalam pengembangannya. Mereka memiliki sumber daya yang kuat, termasuk di dalamnya teknologi kontemporer sebagai modal utama penguasaan pasar. Keunggulan mereka masih ditambah dengan cara mempertahankan hak paten, copy-rights dan intellectual property rights sehingga mempersulit proses transfer teknologi yang diharapkan negara-negara berkembang (Sri Edi Swasono, 2000). Dalam kasus ini, menjadi sangat sulit bagi negara berkembang untuk menjadi pemain dalam industri global.

\section{PENYEBARAN PRODUK GLOBAL VIA FDI}

Perusahaan-perusahaan multinasional selalu mempunyai hasrat besar untuk melakukan ekspansi dalam rangka meningkatkan profitnya. Ekspansi tersebut dilakukan di negara-negara berkembang yang notabene berteknologi rendah. Kebangkitan perekonomian Indonesia pada akhir 80-an hingga pertengahan 90-an banyak dipengaruhi oleh fenomena ini. Pertumbuhan ekonomi Indonesia pada masa itu, adalah kontribusi Foreign Direct Investment dari perusahaan-perusahaan multinasional negara maju. Foreign Direct Investment selalu menjadi solusi bagi Indonesia dalam mengejar pertumbuhan ekonomi.

Keputusan untuk menyebarkan produk global melalui FDI tersebut berimplikasi pada kian kuatnya cengkeraman teknologi kontemporer negara maju di dunia. Yang menjadi masalah, terkadang nilai investasi yang ditanamkan tidak sebanding dengan repatriasi 
yang dibawa kembali ke negara-negara maju. Oleh karena itu Indonesia harus memperkuat aliansinya untuk membendung efek negatif dari FDI ini. Selain itu, untuk memperkuat posisi tawar menawar Indonesia, penguasaan kita terhadap local knowledge harus dipertahankan. Local Knowledge adalah penekanan pengetahuan tentang informasi dan kondisi ekonomi, politik, budaya, dan iklim bisnis setempat ; informasi tentang selera dan permintaan lokal ; selain itu juga informasi tentang akses ke angkatan kerja lokal, jalur distribusi, infrastruktur, bahan baku dan berbagai faktor yang kondusif bagi perkembangan bisnis setempat ( Makino \& Delios, 1996 ).

\section{DAUR HIDUP PRODUK DAN ALIH TEKNOLOGI}

Secara umum telah kita ketahui bersama, bahwa sebuah produk selalu mempunyai siklus hidup. Meskipun masing-masing produk memiliki siklus hidup yang berbeda panjang-pendeknya, namun dalam siklus hidup produk selalu terbagi menjadi 4 bagian, yaitu introduction, growth, maturity dan decline. Tiap-tiap bagian dari daur hidup produk membutuhkan strategi pengembangan produk yang berbeda. Hal ini tentu disesuaikan dengan kondisi suatu produk pada tiap tahapan daur hidupnya. Dalam konteks inovasi teknologi, eksistensi suatu produk tergantung dari tahap introduction dan maturity (Inggridiantara, 1996). Pada dua tahap tersebut, suatu produk dapat dinilai eksis karena keunggulan teknologinya.

Dalam tahap introduction / perkenalan, di mana suatu produk pertama kali masuk pasar, ketepatan teknologi, yang direpresentasikan dari diterimanya produk tersebut oleh konsumen, akan sangat menentukan "nasib" produk itu pada tahapan berikutnya. Kemudian pada saat produk tersebut berada pada tahap maturity / kedewasaan, untuk menjaga agar tidak segera mencapai tahap decline, dibutuhkan inovasi teknologi untuk memperpanjang tahap maturity. Ada dua kemungkinan yang terjadi sebagai ekses inovasi teknologi dalam tahap ini. Pertama, terjadi proses diferensiasi produk yaitu penambahan atribut-atribut produk untuk memperpanjang siklus hidup produk. Kedua, diversifikasi produk, di mana proses inovasi teknologi ini pada akhirnya melahirkan produk baru yang juga menimbulkan siklus hidup produk yang berbeda. 
Pada saat ini, Indonesia hanya menjadi obyek dari teknologi negara maju dalam penyebaran produk-produk global. Oleh karena itu, harapan kita adalah agar proses alih teknologi dari negara maju kepada negara berkembang segera terjadi. Namun, kenyataannya teknologi kunci yang berhubungan dengan produksi dan pemasaran, terkonsentrasi dan dilindungi oleh negara-negara maju tertentu setidak-tidaknya pada awalnya (A. Isaak, 1995). Kondisi ini berlawanan dengan kecurangan negara-negara maju yang mencuri paten produk-produk tertentu negara berkembang. Misalnya kasus Indonesia, di mana hak paten tempe justru dikuasai AS (Sri Tua Arief, 2000).

Daur hidup produk global, apabila dihubungkan dengan proses alih teknologi, dapat digambarkan dengan gambar di bawah ini :

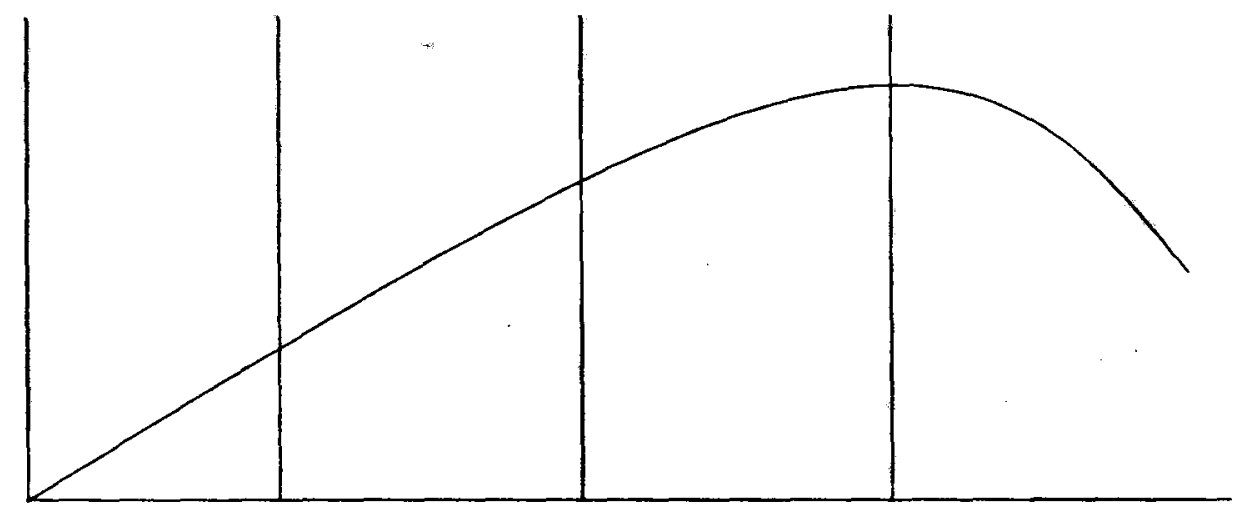

$\begin{array}{llll}\text { Introduction: } & \text { Growth: } & \text { Maturity: } & \text { Decline: } \\ \text { High Patent } & \text { Mass -Production } & \text { Production In } & \text { Mass Production } \\ \text { High Price } & \text { In Developed- } & \text { Developing- } & \text { In Developing } \\ \text { Limited - } & \text { Countries } & \text { Countries } & \text { Countries } \\ \text { Production } & \text { High Patent } & \text { Technology Transfer } & \text { Technology } \\ \text { In Developed- } & & & \text { Obsolence }\end{array}$

Sumber : A. Isaak, 1995, hal 218, di olah

Dari bagan di atas dapat dilihat bahwa proses alih teknologi selalu terjadi pada saat produk tersebut dalam tahap maturity dan teknologinya sudah mendekati keusangan. 


\section{DEKONSTRUKSI INDUSTRI}

Selama ini selalu terjadi perdebatan di antara para ekonom tentang strategi pembangunan yang paling tepat untuk diterapkan di Indonesia, apakah yang berbasis pertanian ataukah industri. Perdebatan tersebut sebenarnya sudah tidak relevan bila dikondisikan dengan situasi terakhir dalam kerangka hubungan negara maju-berkembang. Fokus perhatian kita seharusnya lebih kepada memilih mata rantai industri yang memberikan value tertinggi ( Khasali, 2000).

Satu contoh riil, pabrik sepatu Nike yang meraup keuntungan milyaran dollar tanpa harus membuat sepatu, tetapi karena mereka memegang paten, menguasai pemasaran dan distribusi produk tersebut. Proses manufacturing dari sepatu Nike dilakukan di Indonesia. Kontradiktif dengan kondisi ini, petani Indonesia sudah begitu senang menerima hasil eksport bahan mentah, sementara mereka harus membayar lima kali lipat untuk import produk jadinya. Di sinilah letak kesalahannya, Indonesia tidak memfokuskan diri pada mata rantai industri yang menghasilkan nilai tambah tertinggi.

Pemerintah dan pelaku ekonomi Indonesia selama ini terlalu lama dininabobokkan oleh mimpi indah transfer teknologi. Kenyataannya tanpa dekonstruksi industri nasional, bangsa Indonesia tidak lebih dari "tukang jahit" dalam proses industrialisasi. Padahal, bila di lihat dari prosentase pertumbuhannya, dalam 20 tahun terakhir, sektor industri Indonesia selalu mengalami peningkatan (lihat diagram).

Pertumbuhan Sektor Industri

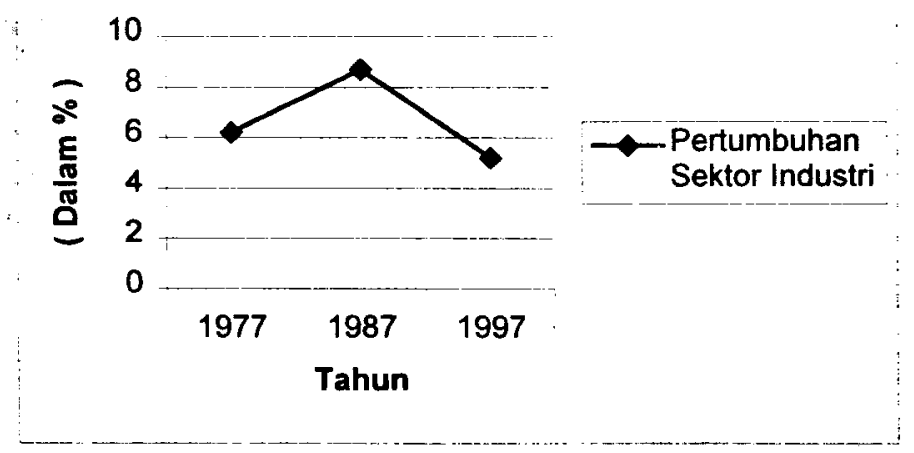

Sumber : World Bank Reports, 98-99 
Penurunan pertumbuhan yang terjadi pada tahun 1997 dikarenakan terpuruknya perekonomian Indonesia sebagai akibat krisis keuangan yang melanda kawasan Asia pada pertengahan 1997. Kondisi ini, tidak mempengaruhi potensi industri Indonesia dalam jangka panjang, karena sampai saat ini Indonesia belum kehilangan dua modal utama dekonstruksi industri, yaitu : Sumber Daya Manusia dan Sumber Daya Alam.

\section{MEMPERKECIL DISPARITAS TEKNOLOGI DENGAN MODAL INTELEKTUAL}

Disparitas teknologi antara negara maju-berkembang sudah saatnya dikurangi, untuk melakukannya Indonesia harus mencari terobosan tanpa mengharapkan terlalu banyak kepada negara-negara maju. Salah satu langkah yang harus dilaksanakan, adalah dengan memperkuat modal intelektual. Modal intelektual adalah materi intelektual-pengetahuan, informasi, hak pemilikan intelektual, pengalaman-yang dapat digunakan untuk menciptakan kekayaan (A. Stewart, 1997). Hal ini dilakukan, mengingat saat ini dasar utama pengembangan teknologi adalah pengetahuan.

Kunci utama dari penguasaan modal intelektual adalah kualitas sumber daya manusia. Karena hardware dari modal intelektual adalah otak manusia. Maka kualitas pendidikan di Indonesia harus diperbaiki. Pola pendidikan di Indonesia harus mencakup tiga hal penting, yaitu conceptual skill, human skill dan technical skill (Alwi, 1999). Dengan berorientasi pada ketiga hal di atas niscaya akan terbentuk sumber daya manusia yang mampu beradaptasi terhadap perekonomian yang berbasis teknologi dan pengetahuan. Namun, langkah ini membutuhkan kerja panjang dan berat karena kondisi umum di Indonesia terkadang lebih buruk dari perkiraan, baik karena faktor politik, ekonomi, budaya dan nilai-nilai tradisional yang menghambat perkembangan sumber daya manusia. 


\section{INOVASI TEKNOLOGI MENUJU RICH LAND AND BIG PEOPLE}

Sumber daya manusia yang berkualitas adalah modal utama inovasi teknologi. Makna SDM yang berkualitas tidak terbatas pada kecerdasan intelektual, namun juga kebebasan berpikir. Dapat dikatakan inovasi teknologi tanpa demokratisasi politik akan bermuara pada penggunaan teknologi untuk melanggengkan kekuasaan pemerintah. Atau dengan kata lain, tanpa demokrasi, teknologi dapat bersifat antidevelopment (Soetrisno, 1997).

Paradigma Rich Land and Big People perlu dikembangkan dalam rangka mengantisipasi teknologi yang tidak membawa kesejahteraan masyarakat. Paradigma ini berpijak dari kenyataan pada masa Orde Baru di mana kebebasan berpikir dibatasi oleh pemerintah sehingga rakyat tidak memiliki access dalam menolak teknologi yang tidak bermanfaat bagi mereka. Negara ini memiliki potensi kekayaan alam yang luar biasa, dan ini direpresentasikan sebagai rich land tetapi kurang memperhatikan kekayaan berpikir rakyatnya atau diistilahkan big people. Dalam era demokratisasi sepert saat ini, keadaan itu harus diubah. Keseimbangan antara pengembangan teknologi fisik dan kebebasan memperoleh access teknologi harus diutamakan.

\section{KESIMPULAN}

Perkembangan produk global saat ini justru menambah asimetri perdagangan internasional, karena kesenjangan perkembangan teknologi negara maju-berkembang demikian lebar. Alih teknologi yang diharapkan negara-negara berkembang ternyata tidak pernah ada, dan jika proses tersebut terjadi biasanya pada saat produk berada dalam tahap maturity atau teknologinya mendekati keusangan.

Sebagai salah satu negara berkembang dengan potensi ekonomi kuat, Indonesia harus melakukan langkah-langkah nyata dalam mengurangi kesenjangan teknologi dan membuat dasar yang kuat bagi tumbuhnya perekonomian berbasis pengetahuan dan teknologi. Beberapa poin yang harus segera dilaksanakan pemerintah dan para pelaku ekonomi nasional, adalah : 
1. Mempertahankan Local Knowledge untuk membendung efek negatif dari Foreign Direct Investment.

2. Melakukan Dekonstruksi Industri dengan berkonsentrasi pada industri yang memberikan nilai tambah tertinggi.

3. Mengejar ketertinggalan teknologi dengan memperkuat modal intelektual.

4. Mengembangkan paradigma Rich Land and Big People dalam rangka memperluas access terhadap teknologi.

\section{DAFTAR PUSTAKA}

Alwi, S, 1996. Nasionalisme Ekonomi Indonesia Dalam Era Kompetisi Global, Jurnal Ekonomi Pembangunan Kajian Ekonomi Negara Berkembang, FE-UII, 4 (1)

Arief, Sri Tua. 2000. Mengenang Bung Hatta Bapak Ekonomi Kerakyatan, Makalah Seminar, Surakarta, MM-UMS.

Budhisetiawan. 1996. Pengaruh Globalisasi Terhadap Daur Hidup Produk, Artikel, Usahawan, 25 (8).

Goldsmith, James. 1995. Perangkap. Jakarta: Yayasan Obor Indonesia

Inggriantara 1996. Daur Hidup Produk Global Dan Strategi Pengembangan Produk, Usahawan 25 (8).

Kasali. 2000. Ekonomi Mikro Sebagai Suplemen Bukan Substitusi Ekonomi Makro, Kumpulan Artikel, Menggugat Masa Lalu Menggagas Masa Depan Ekonomi Indonesia, Jakarta : Kompas.

Makino, S \& Delios, A. 1996. Local Knowledge Transfer And Performance Implications For Alliance Formation In Asia, Journal Of International Bussiness Studies, Special Issue.

Soemardi, P. 1996. Pengaruh Kemajuan Teknologi Dan Pengetahuan Terhadap Daur Hidup Produk Global, Usahawan 25 (8). 
Soetrisno, Lukman. 1997. Rich Land and Big People atau Rich Land and Small People: Pilihan Tujuan Pembangunan di Indonesia, artikel, Demokratisasi Ekonomi dan Pertumbuhan Politik, Yogyakarta: Kanisius.

Stewart, Thomas A. 1997. Intellectual Capital Kekayaan Baru Organisasi, Jakarta: PT Elex Media Komputindo.

Swasono, Sri Edi. 2000. Kiat Merdeka Untuk Menjadi Tuan Di Negeri Sendiri, Makalah Seminar, Surakarta, MM-UMS.

World Bank Annual Reports. 1999. 